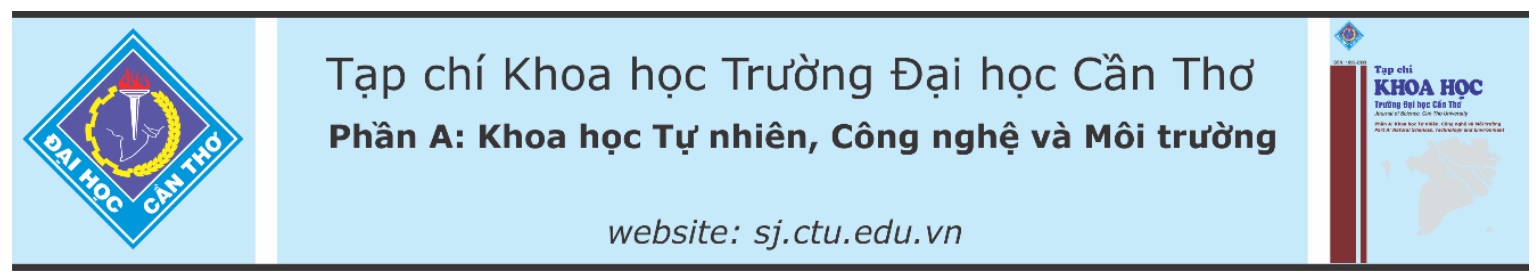

DOI:10.22144/ctu.jvn.2021.081

\title{
TỔNG HỢP VÀ KHẢO SÁT KHẢ NĂNG KHÁNG KHUẨN CỦA NANO BẠC TRONG SƠN NƯỚC NỘI THẤT
}

\author{
Lê Thị Ngọc Hoa, Trần Quang Minh, Huỳnh Trọng Kha và Vũ Năng An* \\ Khoa Khoa học và Công nghệ Vật liệu, Truờng Đại học Khoa học Tụ nhiên, ĐHQG-HCM \\ *Nguoòi chịu trách nhiệm về bài viết:Vũ NăngAn (email: vnan@hcmus.edu.vn)
}

\section{Thông tin chung:}

Ngày nhận bài: $26 / 01 / 2021$

Ngày nhận bài sưa: 27/03/2021

Ngày duyệt đăng: 25/06/2021

\section{Title:}

Synthesis and evaluation of the antibacterial activity of silver nanoparticles in indoor waterborne architectural coating

\section{Tù khóa:}

Hạt nano Ag, hydroxypropyl methylcellulose, phu gia kháng khuẩn, sơn nhũ tuoong nội thất

\section{Keywords:}

Ag nanoparticles, antibacterial additive, hydroxypropyl methylcellulose, indoor waterborne architectural coating

\begin{abstract}
In this study, spherical Ag nanoparticles (Ag NPs) with sizes of $8-12 \mathrm{~nm}$ as an antibacterial additive for indoor waterborne architectural coating have been successfully synthesized by chemical reduction method. This simple and environmentally friendly process is performed with a reducing agent and a protective agent that is glucose (concentration of $0.4 \%$ ) and hydroxypropyl methylcellulose (HPMC_concentration of $0.01 \%$ ), respectively. Next, nano silver solution was added to the paint before adding the emulsion resin. This method maintains the chemical and physical properties of the paint while enhancing the antimicrobial ability from nano silver in the paint. The effectiveness of nano silver as an antibacterial additive for emulsion paints was evaluated on Escherichia coli and Bacillus subtilis using an antibacterial ring method, respectively. The results showed that the emulsion paint was bactericidal with the nano silver content of $0.1-0.5 \mathrm{ppm}$ in the paint. The antimicrobial effect of nano silver in the emulsion paint was maintained for a minimum period of 30 days.
\end{abstract}

\section{TÓM TẮT}

Trong nghiên cứu này, hạt nano Ag (AgNPs) hình cầu với kích thước tù̀ 8 - $12 \mathrm{~nm}$ đã được tổng hợp thành công bằng phuoong pháp khủ hóa học để làm phu gia kháng khuẩn cho sơn nhũ tương nội thất. Phương pháp đơn giản và thân thiện với môi truờng này được tiến hành với tác nhân khử và chất bảo vệ là glucose (nồng độ 0,4\%) và hydroxypropyl methylcellulose (HPMC với nồng độ 0,01\%). Tiếp đến, dung dịch nano bac được cho vào son truớc khi thêm nhưa nhũ tuoơng. Phuoong pháp này vẫn duy trì các tính chất lý hóa của sơn, đồng thời vẫn thêm khả năng kháng khuẩn của nano bac trong sơn. Hiệu quả của nano bạc với vai trò phu gia kháng khuẩn cho son nhũ tuoong được thử nghiệm lần luợt trên Escherichia coli và Bacillus subtilis thông qua phuoong pháp vòng kháng khuẩn. Kết quả cho thấy sơn nhũ tương có khả năng diệt khuẩn khi hàm luợng nano bạc trong son là 0,1-0,5 ppm. Hiệu quả kháng khuẩn của nano bac trong son nhũ tuoong được duy trì trong khoảng thời gian tối thiểu là 30 ngày.

\section{MỞ ĐÀU}

Hiện nay, nhiễm trùng bệnh viện (NTBV) ở nước ta nói riêng và thế giới nói chung đang là một thách thức lớn cho các bệnh viện vì tỉ lệ nhiễm khuẩn ngày càng cao. Tại Hoa Kỳ, Trung tâm Kiểm soát và Phòng ngừa dịch bệnh ước tính có khoảng 1,7 triệu ca NTBV, góp phần gây ra 99.000 ca tử 
vong mỗi năm (Boev \& Kiss, 2017). Nguyên nhân xuất phát từ tất cả các loại vi sinh vật, bao gồm cả vi khuẩn và các loại nấm. Kết quả cuộc khảo sát bệnh viện được tiến hành tại châu Âu cho thấy nhiễm trùng từ các loại vi khuẩn Gram âm ước tính chiếm khoảng $2 / 3$ trong số 25.000 ca tử vong mỗi năm (Sharma et al., 2009). NTBV có thể gây viêm phổi nặng, nhiễm trùng đường tiết niệu, máu và các bộ phận khác của cơ thể. Nhiều loại khó điều trị với thuốc kháng sinh. Ngoài ra, các vi khuẩn đề kháng kháng sinh có thể làm việc điều trị trở nên phức tạp. NTBV làm tăng khả năng đề kháng của thuốc vì bệnh viện là nơi tập trung sử dụng các kháng sinh trong điều trị, đặc biệt đối với các bệnh nặng, do vậy các vi khuẩn có điều kiện tiếp xúc với nhiều loại kháng sinh và các kháng sinh mới (Klasen, 2000; Pauksch et al., 2014). Bệnh có thể lan truyền từ các nhân viên y tế, cũng như các dụng cụ y tế không được sát trùng kỹ, khăn trải giường, hoặc cả từ không khí. Nhiễm trùng cũng có thể lan truyền từ các bệnh nhân khác nhau. Trong một số trường hợp, các vi sinh vật có nguồn gốc từ da của bệnh nhân, xâm nhập vào trong cơ thể sau khi giải phẫu. Mặc dù bệnh nhân có thể đã nhiễm bệnh từ chính da của mình, việc nhiễm trùng vẫn được coi là NTBV vì nó phát triển trong môi trường chăm sóc sức khỏe (Sharma et al., 2009).

Một trong những cách kiểm soát nhiễm trùng và phòng ngừa tại bệnh viện là phải lau chùi, tẩy uế và vệ sinh các bề mặt môi trường bệnh viện, trong đó có cả lớp sơn nội thất trong phòng bệnh. Sơn nội thất ngoài công dụng để bảo quản, giúp các bề mặt hoàn thiện có độ nhẵn mịn cao, mỹ quan với màu sắc đa dạng, tươi đẹp, có tuổi thọ cao, có độ che phủ tốt, dễ dàng thi công,... mà còn giúp tăng tính an toàn vệ sinh trong quá trình sử dụng. Hiện nay, từ thực tiễn về NTBV, một số hãng sơn đã nghiên cứu, vận dụng và đưa vào trong thành phần của sơn các phụ gia kháng khuẩn giúp kiểm soát, hỗ trợ ngăn chặn sự lây lan, và tái lây nhiễm của các vi khuẩn ngay trên bề mặt các bức tường nhà ở và môi trường sinh hoạt.

Các phụ gia kháng khuẩn kể trên khá đa dạng, bao gồm chlorothalonil (CTL), zinc pyrithione (ZPT), 3-iodopropargyl-nbutylcarbamate (IPBC), 2-n-octyl-4-isothiazolin-3-one (OIT), 4,5dichloro-2-(n-octyl)-4-isothiazolin-3-one (DCOIT) và carbendazim (CBZ) (Dileep et al., 2020; Zuniga $\&$ Cortes, 2020). Trong số đó, các loại sơn có chứa các hạt nano bạc (AgNPs) cho thấy hiệu quả kháng khuẩn tốt, có khả năng tiêu diệt cả vi khuẩn Gram dương và Gram âm cụ thể như là Staphylococcus aureus và Escherichia coli. Tuy tính chất kháng khuẩn của AgNPs chưa được hiểu rõ và đầy đủ, nhưng một số nghiên cứu đã chứng minh rằng AgNPs gắn vào màng tế bào vi khuẩn làm thay đồi tính thấm và làm rối loạn chức năng hô hấp của màng tế bào và từ đó làm vi khuẩn bị tiêu diệt (Ahamed et al., 2010; Bruchez et al., 1998; Cui et al., 2001). Nhiều nghiên cứu đã được công bố về việc kết hợp AgNPs vào sơn (Kumar et al., 2008), thiết bị y tế (Furno et al., 2004) và các sản phẩm thương mại khác nhằm mục đích chủ yếu là bảo vệ sức khỏe người sử dụng.

$\mathrm{AgNPs}$ có thể được tổng hợp bằng nhiều phương pháp, như khử bằng bức xạ UV (Liu et al., 2009), xử lý vi sóng (Wani et al., 2011), phân hủy nhiệt (Shim et al., 2008), phương pháp điện phân (Liu et al., 2012), cấy ion (Popok et al., 2005), khử hóa học (Khan et al., 2011; Vitulli et al., 2002),... Trong đó, quá trình khử hóa học là phương pháp phổ biến nhất. Phương pháp này không chỉ đòi hỏi quy trình và thiết bị đơn giản mà còn có khả năng tổng hợp các hạt nano với kích thước đồng nhất (Liu et al., 2010; Raveendran et al., 2006; Sun \& Xia, 2002). Tuy nhiên, hầu hết các quá trình khử hóa học thông thường đều sử dụng chất khử, chất ổn định và / hoặc dung môi độc hại (Fabrega et al., 2011; Jiang et al., 2011; Liu et al., 2010). Trên cơ sở đó, mục đích của nghiên cứu này là tổng hợp $\mathrm{AgNPs}$ bằng phương pháp thân thiện môi trường. AgNPs được tổng hợp từ các ion $\mathrm{Ag}^{+}$bằng quá trình khử một giai đoạn trong dung môi nước, sử dụng chất ổn định là hydroxypropyl methylcellulose (HPMC) và chất khử là glucose, đều là các tác chất thân thiện với môi trường và có khả năng phân hủy sinh học. Ngoài ra, quá trình không cần sử dụng thêm bất kỳ chất xúc tiến nào. Tiếp đến, $A g N P s$ được đưa vào sơn nhũ tương với tiêu chí không làm giảm các tính chất lý hóa của sơn, đồng thời vẫn duy trì được khả năng kháng khuẩn của AgNPs trong sơn. Hiện nay sơn nano bạc thường được điều chế bằng cách mua sơn thành phẩm ngoài thị trường, sau đó mới trộn với nano bạc. Điều này làm cho sơn thành phẩm thường bị tách pha do không có tính liên tục giữa các pha, dẫn đến AgNPs chỉ hiện diện trên bề mặt sau khi sơn và thường bị rửa trôi rất nhanh. Đây chính là nguyên nhân chính dẫn đến thất bại trong các nghiên cứu sơn có nano bạc. Trong nghiên cứu này, dung dịch nano bạc được cho vào sơn trước khi thêm nhựa nhũ tương, ở giai đoạn nạp nhựa. Điều này nhằm đảm bảo AgNPs hiện diện trong toàn bộ cấu trúc của sơn, giúp ngăn chặn hiện tượng tách pha và rửa trôi trong quá trình hình thành và sử dụng màng sơn. Đây chính là điểm khác biệt rõ rệt và cũng là tính mới 
của nghiên cứu này. Hiệu quả của nano bạc với vai trò phụ gia kháng khuẩn cho sơn nhũ tương được thử nghiệm lần lượt trên Escherichia coli $(E$. coli) và Bacillus subtilis (B. subtilis) thông qua phương pháp vòng kháng khuẩn.

\section{VẬT LIỆU VÀ PHƯƠNG PHÁP}

\subsection{Vật liệu}

Hydroxypropyl methylcellulose (HPMC) được cung cấp bởi hãng Shin-etsu (Nhật Bản), với các thông số kỹ thuật như sau: độ nhớt của dung dịch $2 \%$ (khối lượng) là $100.000 \mathrm{mPa}-\mathrm{s}$ (cps), đo tại $20^{\circ} \mathrm{C}$. Thành phần methoxy là $19,0-24,0 \%$ và hydroxypropyl là $4,0-12,0 \% \cdot \operatorname{Al}\left(\mathrm{NO}_{3}\right)_{3} \cdot 9 \mathrm{H}_{2} \mathrm{O}$, ascorbic acid, glucose, cùng tiền chất của $\mathrm{Ag}$ là $\mathrm{AgNO}_{3}$ đều là dạng thương mại, có xuất xứ từ Trung Quốc. Tất cả các hóa chất đều được sử dụng trực tiếp và pha trong nước cất hai lần mà không cần qua bất kỳ quá trình tinh chế nào.

Các hóa chất được sử dụng để điều chế sơn nhũ tương đều là các hóa chất công nghiệp được thương mại hóa trên thị trường. Nhựa nhũ tương acrylic sử dụng là loại Viscopol 2030 - Nuplex. Các phụ gia bao gồm: Orotan 1124, Strodex TH100, Drewplus T4507A, Natrosol 250HBR (HEC), pHflex 110, Ropaque Ultra và Texanol. Trong nghiên cứu này, sơn được sử dụng chất độn và chất làm đầy là bột đá $\left(\mathrm{CaCO}_{3}\right)$, với các thông số kỹ thuật là D50 4 $\mu \mathrm{m}$, D97 $20 \mu \mathrm{m}$, độ trắng > 98\%, và cao lanh; cùng chất tạo độ che phủ là $\mathrm{TiO}_{2}$ (Rutile) - R706. Chất độn và chất làm đầy đều là các hóa chất có nguồn gốc từ Việt Nam.

\subsection{Quy trình thực nghiệm \& phương pháp nghiên cứu}

\subsubsection{Quy trình tổng hợp nano bạc}

Trong nghiên cứu này, các hạt nano $\mathrm{Ag}(\mathrm{AgNPs})$ được tổng hợp bằng phương pháp dung dịch với chất bảo vệ là $H P M C$ và glucose đóng vai trò làm chất khử. Quy trình thực nghiệm được tiến hành như sau: đầu tiên, $0,01 \mathrm{~g}$ HPMC được thêm vào $70 \mathrm{~mL}$ nước cất hai lần. Hỗn hợp được khuấy từ và gia nhiệt ở $50^{\circ} \mathrm{C}$ cho đến khi HPMC tan hoàn toàn, thu được dung dịch trong suốt. Tiếp đến, $10 \mathrm{~mL}$ dung dịch $\mathrm{AgNO}_{3} 0,05 \mathrm{M}$ được thêm vào dung dịch $\mathrm{HPMC}$ và khuấy liên tục để thu được dung dịch $\mathrm{Ag}^{+} / \mathrm{HPMC}$. Sau đó, $20 \mathrm{~mL}$ dung dịch glucose $2 \%$ (khối lượng/thể tích) được thêm vào dung dịch trên (tổng thể tích dung dịch phản ứng là $100 \mathrm{~mL}$ ). Dung dịch được khuấy liên tục ở $90^{\circ} \mathrm{C}$ trong 9 giờ. Kết thúc thời gian, dung dịch thu được có màu vàng, được ký hiệu là C318. Cuối cùng, dung dịch ascorbic acid ở nồng độ 25 ppm, được nhỏ từ từ vào dung dịch $\mathrm{C} 318$ với tốc độ 1 giọt/3 giây. Dung dịch được khuấy nhanh ở tốc độ khoảng 1.000 vòng/phút cho đến khi màu sắc dung dịch chuyển từ vàng sang cam đến nâu đen.

Kích thước và hình thái của $\mathrm{AgNPs}$ được xác định qua ảnh hiển vi điện tử truyền qua (TEM) trên thiết bị JEM 1400 (JEOL) với thế gia tốc $100 \mathrm{kV}$. Mẫu đo TEM được nhỏ lên trên lưới đồng và phủ lên một lớp carbon mỏng, tiếp đến mẫu được sấy khô trước khi phân tích. Mẫu khô dạng bột được phân tích nhiễu xạ tia X (XRD_D2 PHARSER, Bruker), sử dụng bức xạ $\mathrm{CuK} \alpha$ với bước sóng $\lambda=$ $1,5406 \AA$ cùng góc quét $2 \theta$ từ $10^{\circ}$ đến $80^{\circ}$ với bước chuyển $0,02 \%$ phút. Phổ hấp thu UV-Vis của dung dịch được đo tại nhiệt độ phòng bằng máy quang phổ UV-VIS-NIR-V670 (Jasco), trong vùng bước sóng từ $200-800 \mathrm{~nm}$, với tốc độ $400 \mathrm{~nm} /$ phút. Sự ổn định của dung dịch nano $\mathrm{Ag}$ sau khi tổng hợp được xác định thông qua giá trị thế zeta được phân tích trên thiết bị Zetasizer Nano ZS (Malvern).

\subsubsection{Xác định độ chuyển hóa $\mathrm{Ag}^{+}$thành $\mathrm{Ag}$}

Nồng độ của nano $\mathrm{Ag}$ được tính bằng cách lấy nồng độ $\mathrm{Ag}^{+}$ban đầu trừ đi nồng độ ion $\mathrm{Ag}^{+}$còn lại sau quá trình khử. Trong nghiên cứu này, nồng độ $\mathrm{Ag}$ được xác định gián tiếp thông qua việc tách $\mathrm{Ag}$ ra khỏi dung dịch keo bằng cách keo tụ, sử dụng chất điện ly là muối $\mathrm{Al}\left(\mathrm{NO}_{3}\right)_{3} \cdot 9 \mathrm{H}_{2} \mathrm{O}$. Phương pháp tiến hành bao gồm các bước như sau: đầu tiên, $20 \mathrm{~mL}$ dung dịch $\mathrm{C} 318$ được thêm vào $30 \mathrm{~g}$ muối $\mathrm{Al}\left(\mathrm{NO}_{3}\right)_{3} \cdot 9 \mathrm{H}_{2} \mathrm{O}$. Tiếp đến, hỗn hợp được khuấy nhẹ trong thời gian 90 phút. Kết thúc thời gian, hỗn hợp được tiến hành ly tâm ở $20^{\circ} \mathrm{C}$ với tốc độ 15.000 vòng/phút, thu được kết tủa màu xám và dung dịch sau ly tâm trong suốt. Mẫu dung dịch ban đầu C318 và dung dịch trong suốt sau ly tâm được tiến hành phân tích phổ hấp thu nguyên tử (AAS) trên thiết bị 240FS AA - Agilent ở cùng điều kiện. Kết quả AAS thu được từ mẫu dung dịch ban đầu $\mathrm{C} 318$, là tổng nồng độ $\mathrm{Ag}$ và $\mathrm{Ag}^{+}$. Kết quả thu được từ dung dịch sau ly tâm là nồng độ $\mathrm{Ag}^{+}$trong dung dịch chưa chuyển hóa thành $\mathrm{Ag}$. Như vậy nồng độ nano $\mathrm{Ag}$ (ppm) thu được sau phản ứng được tính theo công thức (1)

Nồng độ nano $\mathrm{Ag}(\mathrm{ppm})=$ (Tổng nồng độ nano $\mathrm{Ag}$ và $\left.\mathrm{Ag}^{+}\right)$- (Nồng độ $\left.\mathrm{Ag}^{+}\right)$

\subsection{3. Điều chế son PLI65}

Sơn PLI65 được điều chế nhằm đáp ứng theo tiêu chuẩn của sơn nội thất Việt Nam (TCVN 8652:2012). Thành phần nhựa nhũ tương chiếm $30 \%$ tổng khối lượng, $\mathrm{TiO}_{2}$ chiếm $15 \%$. Đây là 2 thành phần chính quyết định chất lượng và giá thành 
của sơn. Thông thường, sơn nhũ tương luôn sử dụng chất kháng khuẩn (biocide), với mục đích bảo quản sơn khỏi tác hại của vi khuẩn trong quá trình lưu trữ. Các chất kháng khuẩn thường ăn da và gây độc cho môi trường. Vì vậy, trong công thức của sơn PLI65 và sơn PLI65-Ag trong nghiên cứu này đều không sử dụng các chất dạng này, và được thay thế bởi dung dịch nano $\mathrm{Ag}$ được tông hợp như trình bày ở phần trên.

Công thức điều chế sơn PLI65 được liệt kê trong Bảng 1 và quá trình điều chế được chia thành 3 giai đoạn chính, được thực hiện trên máy trộn - nghiền sơn Siemens (Hình 1) bao gồm các công đoạn là phân tán, nghiền và nạp nhựa (let-down).

Giai đoạn phân tán
Trong giai đoạn này, dung dịch bao gồm dung môi là nước, chất hoạt động bề mặt, chất hỗ trợ phân tán và chất phá bọt được khuấy ở tốc độ thấp để tránh tạo bọt nhưng phải đảm bảo dung dịch tạo thành đồng nhất. Đây là bước chuẩn bị cho giai đoạn đưa vào các chất độn và chất tạo độ phủ dạng bột như $\mathrm{CaCO}_{3}$, cao lanh và $\mathrm{TiO}_{2}$.

Các nguyên liệu dạng rắn được thêm vào như đã liệt kê ở Bảng 1 . Hỗn hợp lúc này có độ nhớt thấp nên cần thêm vào nguyên liệu tạo đặc để tăng độ nhớt. Chất tạo đặc được sử dụng là dạng HEC (hydroxyethyl cellulose), tên thương mại Natrosol 250 HBR. Chất tạo đặc được phân tán vào nước cho thấm ướt đều và trương nở, sau đó cho vào hỗn hợp để bắt đầu giai đoạn nghiền.

\section{Bảng 1. Công thức điều chế sơn PLI65}

\begin{tabular}{|c|c|c|c|c|}
\hline \multicolumn{5}{|c|}{ I. Khuấy ở tốc độ thấp, phân tán đến khi hỗn hợp đồng nhất (100-150 vòng/phút) } \\
\hline STT & Thành phần & Vai trò & Đơn vị & Giá trị \\
\hline 1 & Nước & Dung môi & $\mathrm{g}$ & 200,0 \\
\hline 2 & Orotan 1124 & Chất phân tán & $\mathrm{g}$ & 4,0 \\
\hline 3 & Strodex TH100 & HĐBM & $\mathrm{g}$ & 3,0 \\
\hline 4 & Drewplus T4507A & Phá bọt & g & 2,0 \\
\hline \multicolumn{5}{|c|}{ II. Tăng dần tốc đô 800 - 900 vòng/phút } \\
\hline 5 & Bột đá & Chất độn & $\mathrm{g}$ & 65,0 \\
\hline 6 & Cao lanh & Chất làm đầy & g & 35,0 \\
\hline 7 & $\mathrm{TiO}_{2}$ (dạng rutile) & Tạo độ phủ, trắng & $\mathrm{g}$ & 150,0 \\
\hline \multicolumn{5}{|c|}{ III. Tạo hỗn hợp premix } \\
\hline 8 & Nước & Hòa tan chất tạo đặc & $\mathrm{g}$ & 30,0 \\
\hline 9 & Natrosol $250 \mathrm{HBR}$ & Chất tạo đặc & $\mathrm{g}$ & 5,0 \\
\hline 10 & pHflex 110 & Tăng pH & $\mathrm{g}$ & 1,0 \\
\hline \multicolumn{5}{|c|}{ IV. Tăng tốc độ khuấy 3000 vòng/phút. $20-30$ phút. Độ mịn $<40$ mm } \\
\hline 11 & Nước & Giải nhiệt & $\mathrm{g}$ & 20,0 \\
\hline \multicolumn{5}{|c|}{ V. Nhiệt độ $<50\left({ }^{\circ} \mathrm{C}\right)$, tốc độ khuấy $350-400$ vòng/phút đến khi hỗn hợp đồng nhất } \\
\hline 12 & Nước & Giải nhiệt và bù khối lượng & $\mathrm{g}$ & 114,0 \\
\hline 13 & Viscopol 2030 & Nhựa nhũ tương acrylic & $\mathrm{g}$ & 300,0 \\
\hline 14 & Texanol & Trợ tạo màng & $\mathrm{g}$ & 18,0 \\
\hline 15 & Ropaque Ultra & Tạo độ bóng & $\mathrm{g}$ & 30,0 \\
\hline 16 & pHflex 110 & Tạo pH & $\mathrm{g}$ & 1,0 \\
\hline 17 & Drewplus T4507A & Phá bọt & $\mathrm{g}$ & 3,0 \\
\hline 18 & Nước & Pha loãng & $\mathrm{g}$ & 20,0 \\
\hline \multicolumn{3}{|c|}{ Cộng } & $\mathrm{g}$ & $1.000,0$ \\
\hline
\end{tabular}




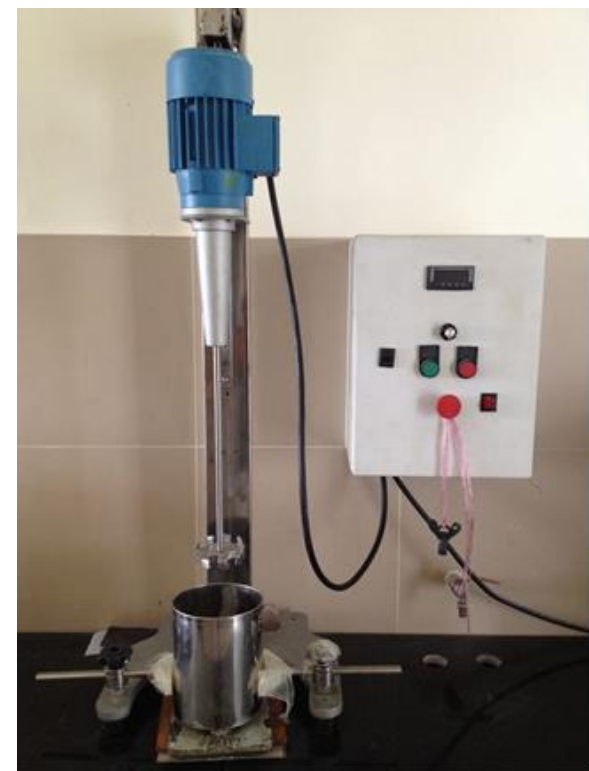

Hình 1. Máy trộn - nghiền sơn Siemens

\section{Giai đoạn nghiền}

Sau khi chất tạo đặc được cho vào, tốc độ khuấy của hỗn hợp được tăng đến khoảng 3.000 vòng/phút. Sau thời gian khuấy từ $20-30$ phút, tùy theo kích thước ban đầu của các nguyên liệu rắn, hỗn hợp được kiểm tra độ mịn bằng thước đo độ mịn (Hình 2). Nhỏ 1 giọt dung dịch lên thước ở nơi có độ sâu lớn nhất và kéo về phía cạn nhất (về phía trái như trong Hình 2).

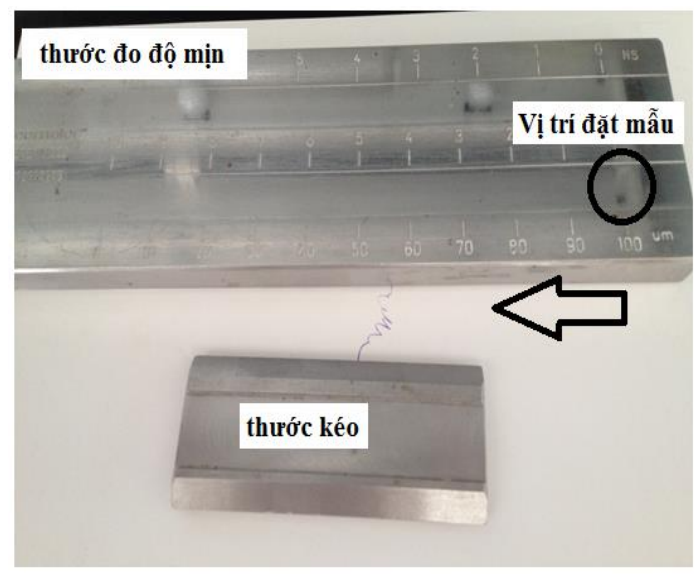

Hình 2. Thước kiểm tra độ mịn của sơn
Quan sát bằng mắt thường sẽ thấy hạt phân bố trên thước. Yêu cầu của sơn nhũ tương theo TCVN 2091:2015 là hạt lớn nhất có đường kính không quá $40 \mu \mathrm{m}$.

\section{Giai đoạn nap nhưa (let-down)}

Trong giai đoạn này, hỗn hợp được giảm tốc độ khuấy. Nhựa nhũ tương được thêm vào đủ lượng đã được cho theo công thức trên Bảng 1 . Hoàn tất việc thêm các nguyên liệu còn lại ở giai đoạn này. Kết thúc quá trình điều chế sơn PLI65 (Hình 3). Sơn được đậy kín, lưu trữ ở nơi tránh ánh sáng chiếu trực tiếp, khô mát.

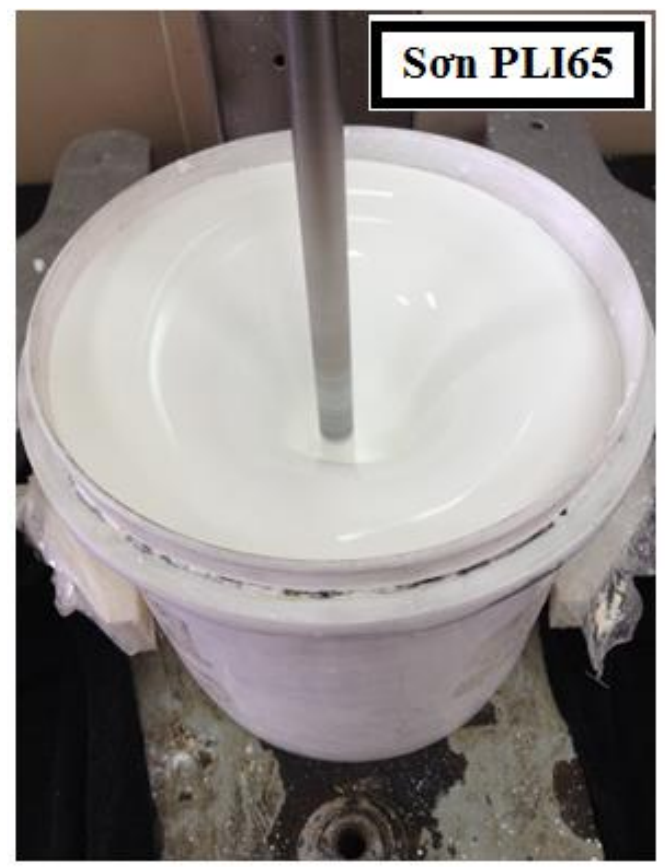

\section{Hình 3. Sơn PLI65 đã được điều chế}

\subsection{4. Điều chế son PLI65 có nano bac (PLI65- Ag)}

Sơn PLI65-Ag được điều chế theo quy trình tương tự như điều chế sơn PLI65, với nồng độ nano Ag khác nhau bao gồm 0,$1 ; 0,5 ; 1,0 ; 5,0 ; 10,0 ; 30,0$ và $50,0 \mathrm{ppm}$. Dung dịch nano $\mathrm{Ag}$ thêm vào được bù trừ bởi lượng nước trong công thức nhằm đảm bảo tổng khối lượng sơn là $1.000 \mathrm{~g}$. Hình 4 là hình ảnh của sơn PLI65-Ag được điều chế ở các nồng độ $\mathrm{Ag}$ khác nhau. 


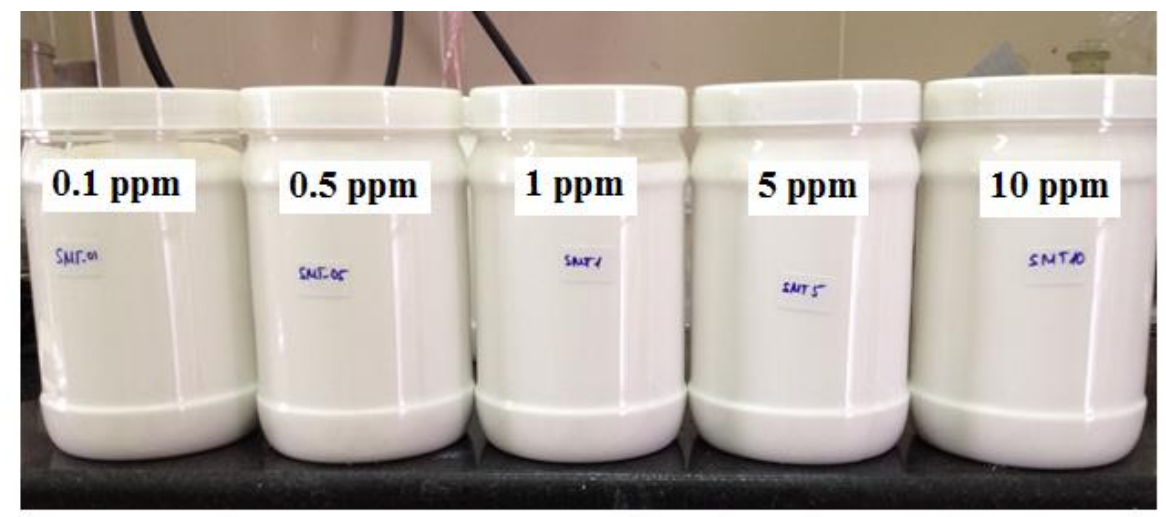

Hình 4. Sơn PLI65-Ag được điều chế ở các nồng độ Ag khác nhau

2.2.5. Các phưong pháp thư nghiệm tính chất của son PLI65 và PLI65-Ag theo tiêu chuẩn Việt Nam

TCVN 2102: 2008 Sơn. Phương pháp xác định màu sắc.

TCVN 2091: 2015 Sơn. Phương pháp xác định độ mịn.

TCVN 2097: 2015 Sơn. Phương pháp cắt, xác định độ bám dính của màng.

TCVN 2096-1: 2015 Sơn. Phương pháp xác định độ khô và thời gian khô.

TCVN 10518-1: 2014 Sơn. Phương pháp xác định hàm lượng chất không bay hơi.

TCVN 9879: 2013 Sơn. Phương pháp xác định độ nhớt.

TCVN 8653-2: 2012 Sơn. Phương pháp xác định độ bền nước.

TCVN 8653-3: 2012 Sơn. Phương pháp xác định độ bền kiềm.

TCVN 8653-4: 2012 Sơn. Phương pháp xác định độ rửa trôi.

\subsection{Khảo sát khả năng kháng khuẩn của sơn PLI65 và PLI65-Ag}

Khả năng kháng khuẩn của sơn được khảo sát bằng phương pháp vòng kháng khuẩn. Quy trình khảo sát được tiến hành như sau: đầu tiên, thạch (agar) được trộn với môi trường để vi khuẩn phát triển, nấu sôi để nguội. Vi khuẩn được trộn vào agar khi agar còn đang dạng lỏng và khuấy đều với nồng độ $10^{6} \mathrm{CFU} / \mathrm{mL}$. Đổ hỗn hợp agar vào đĩa petri đường kính $90 \mathrm{~mm}$. Thử nghiệm lần lượt trên $E$. coli và $B$. subtilis.

\section{Đối với mẫu sơn dạng lỏng}

Sau khi thạch đã đông, tiến hành tạo giếng (well). Sơn được đổ đầy vào giếng. Ghi nhãn vi khuẩn và tên mẫu. Đậy bằng 1 đĩa petri khác và ủ nhiệt ở $37^{\circ} \mathrm{C}$ trong 24 giờ để vi khuẩn phát triển. Sau đó mẫu được quan sát bằng mắt và ghi nhận lại bằng hình ảnh.

\section{Đối với son khô}

Dùng giấy lọc đường kính $11 \mathrm{~cm}$, sơn 2 lớp bằng cọ lăn cách nhau 30 phút. Mẫu được sơn cả 2 mặt. Sau 24 giờ cắt thành hình vuông nhỏ có cạnh $1 \mathrm{~cm}$. Mẫu sau đó để khô tự nhiên trong 30 ngày, sau đó tiến hành thử nghiệm đo vòng kháng khuẩn.

Thạch được chuẩn bị tương tự như đối với sơn dạng lỏng, mẫu đặt lên bề mặt khi thạch đã đông. Đậy bằng đĩa petri, ủ nhiệt ở $37^{\circ} \mathrm{C}$ trong 24 giờ để vi khuẩn phát triển. Sau đó mẫu được quan sát bằng mắt và ghi nhận lại bằng hình ảnh.

\subsection{Khảo sát khả năng phóng thích ion $\mathbf{A g}^{+}$ của sơn PLI65-Ag}

Các mẫu sơn PLI65-Ag với hàm lượng nano bạc khác nhau được sơn lên giấy lọc và để khô tự nhiên trong 30 ngày. Sau đó tiến hành xác định hàm lượng ion $\mathrm{Ag}^{+}$được phóng thích trong môi trường nước ở thời gian ngắn từ $1-4$ giờ. Hàm lượng ion $\mathrm{Ag}^{+}$được xác định bằng phương pháp phổ hấp thu nguyên tử (AAS) trên thiết bị 240FS AA - Agilent.

\section{KẾT QUẢ THẢO LUẬN}

\subsection{Tổng hợp hạt nano bạc (AgNPs)}

Phổ hấp thu UV-Vis của dung dịch C318 và giản đồ XRD của mẫu rắn cô lập sau phản ứng được hiển thị trên Hình 5. Kết quả phân tích phổ UV-Vis (Hình $5 a)$ của dung dịch xuất hiện mũi hấp thu ở bước sóng $400-420 \mathrm{~nm}$, đặc trưng cho cộng hưởng plasmon bề mặt của AgNPs (Dong et al., 2014). Ngoài ra, kết quả XRD (Hình $5 b$ ) cũng xác minh sự tồn tại cấu 
trúc tinh thể của AgNPs thông qua sự hiện diện của các đỉnh nhiễu xạ tại các giá trị $2 \theta=38,30^{\circ} ; 44,45^{\circ}$; $64,55^{\circ}$ và $77,48^{\circ}$ tương ứng với các mặt mạng tinh thể (111), (200), (220), và (311) trong cấu trúc lập

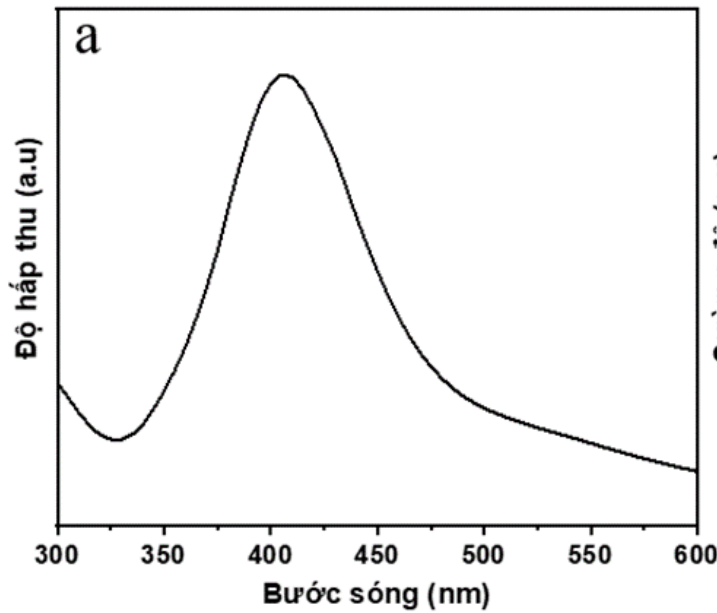

phương tâm mặt (FCC) của AgNPs (JCPDS No. 870717) (Dong et al., 2014). Ngoài ra, đỉnh nhiễu xạ rộng còn chỉ ra rằng các hạt $\mathrm{Ag}$ thu được trong dung dịch là các hạt có kích thước nano.

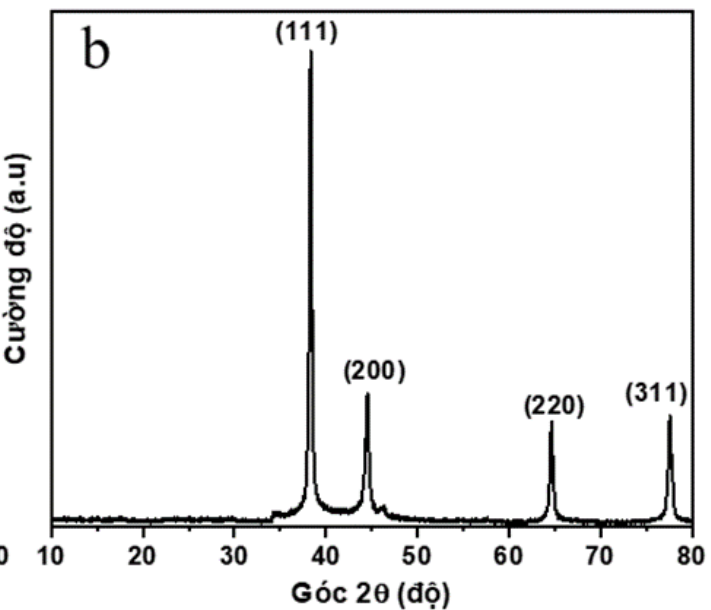

Hình 5. Phổ hấp thu UV-Vis của dung dịch nano Ag (a) và giản đồ XRD (b) của nano $\mathrm{Ag}$
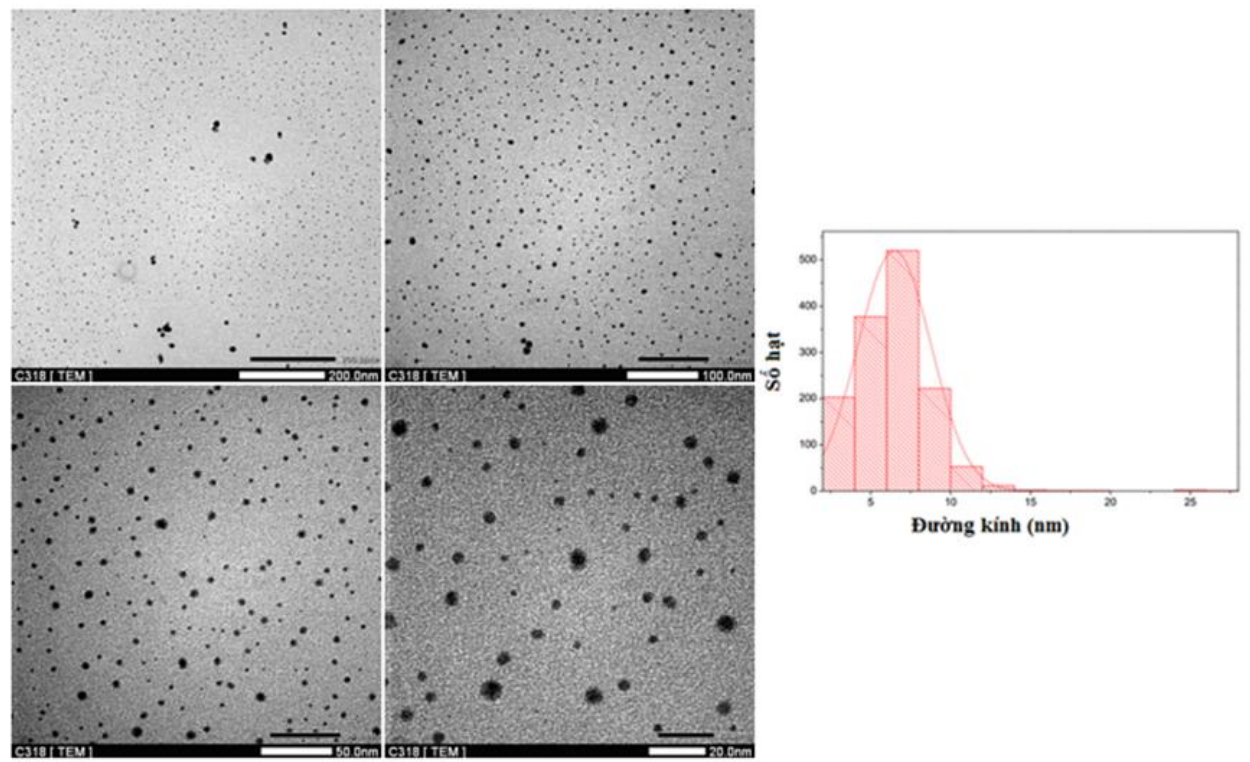

Hình 6. Ảnh TEM ở các thang đo khác nhau và sự phân bố kích thước của AgNPs

Ảnh TEM của mẫu C318 (Hình 6) thu được cho thấy các AgNPs tồn tại trong dung dịch có mật độ cao và khoảng cách giữa các hạt tương đối đồng đều. Điều này cho thấy AgNPs trong dung dịch có hàm lượng cao mà vẫn không xảy ra hiện tượng tập hợp dẫn đến sa lắng. Hơn nữa, thống kê về kích thước và phân bố kích thước cho kết quả AgNPs có độ đa phân tán thấp, chứng tỏ các hạt đồng đều nhau và phân bố trong khoảng nhỏ hơn $15 \mathrm{~nm}$. Các hạt kích thước trên $15 \mathrm{~nm}$ xuất hiện không đáng kể. Như vậy có thể thấy, quy trình sử dụng trong nghiên cứu này hiệu quả trong việc tổng hợp nano bạc kích thước 5 $-10 \mathrm{~nm}$. 


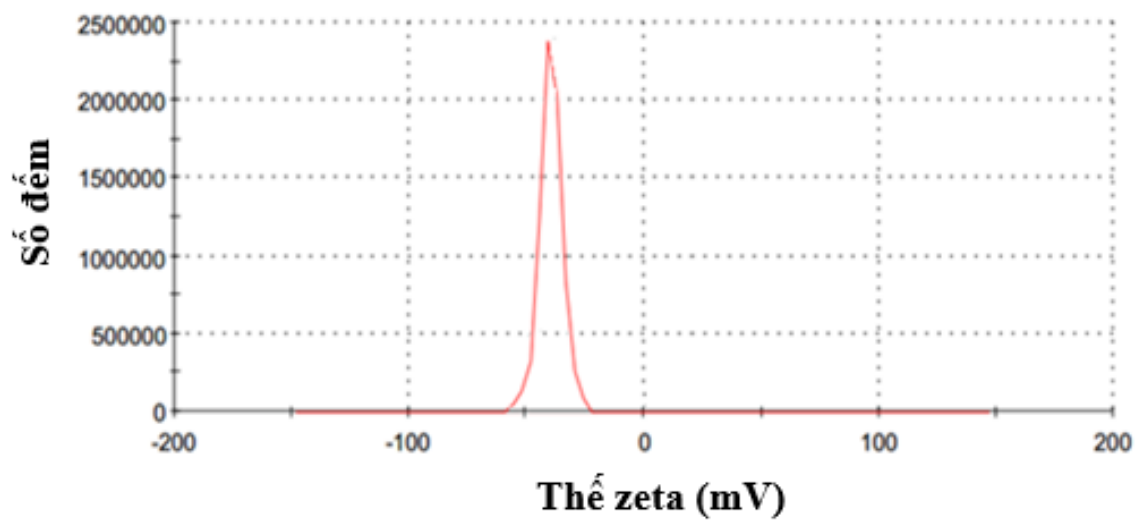

Hình 7. Thế zeta của dung dịch nano bạc

Tiếp đến, dung dịch C318 được đo thế zeta nhằm xác định độ ổn định của dung dịch keo Ag. Kết quả thế zeta (Hình 7) cho thấy hệ keo bền và không bị tập hợp. Các hạt keo mang điện dương và có lớp ion nghịch là $-37,21 \mathrm{mV}$. Thế zeta âm hơn $-30 \mathrm{mV}$ đủ để duy trì lực đẩy cần thiết, giữ cho các hạt keo không bị tụ lại với nhau.

Như vậy, thông qua các kết quả phân tích trên, đã chứng minh rằng AgNPs đã được tổng hợp thành công bằng phương pháp khử hóa học với tác nhân khử và chất bảo vệ thân thiện môi trường là glucose (nồng độ $0,4 \%$ ) và HPMC (nồng độ $0,01 \%$ ). $\mathrm{AgNPs}$ thu được có dạng hình cầu, kích thước tương đối đồng đều từ $8-12 \mathrm{~nm}$. Dung dịch keo $\mathrm{Ag}$ sau phản ứng có thế zeta phù hợp để duy trì độ ổn định, tránh hiện tượng kết tụ lại. Đây là những kết quả khả quan, được tiếp tục sử dụng để điều chế sơn PLI65-Ag.
Hàm lượng của nano $\mathrm{Ag}$ tạo thành sau phản ứng được xác định bằng phương pháp keo tụ. Nồng độ của $\mathrm{Ag}(\mathrm{ppm})$ của dung dịch $\mathrm{C} 318$ ban đầu và dung dịch C318 ly tâm sau quá trình keo tụ được phân tích AAS cho kết quả lần lượt là 578,0 và 337,5 ppm. Như vậy hàm lượng nano $\mathrm{Ag}$ được tính theo công thức (1)

Hàm lượng nano $\mathrm{Ag}=$ (Nồng độ $\mathrm{Ag}$ trong dung dịch C318) - (Nồng độ $\mathrm{Ag}$ mẫu dung dịch ly tâm sau keo tụ $) \times(32,96 / 20)=22 \mathrm{ppm}$.

Trong đó, 20 (g) là khối lượng dung dịch C318 và 32,96 (g) là khối lượng dung dịch sau khi đã tính thêm lượng nước có trong $30 \quad(\mathrm{~g})$ muối $\mathrm{Al}\left(\mathrm{NO}_{3}\right)_{3} \cdot 9 \mathrm{H}_{2} \mathrm{O}$.

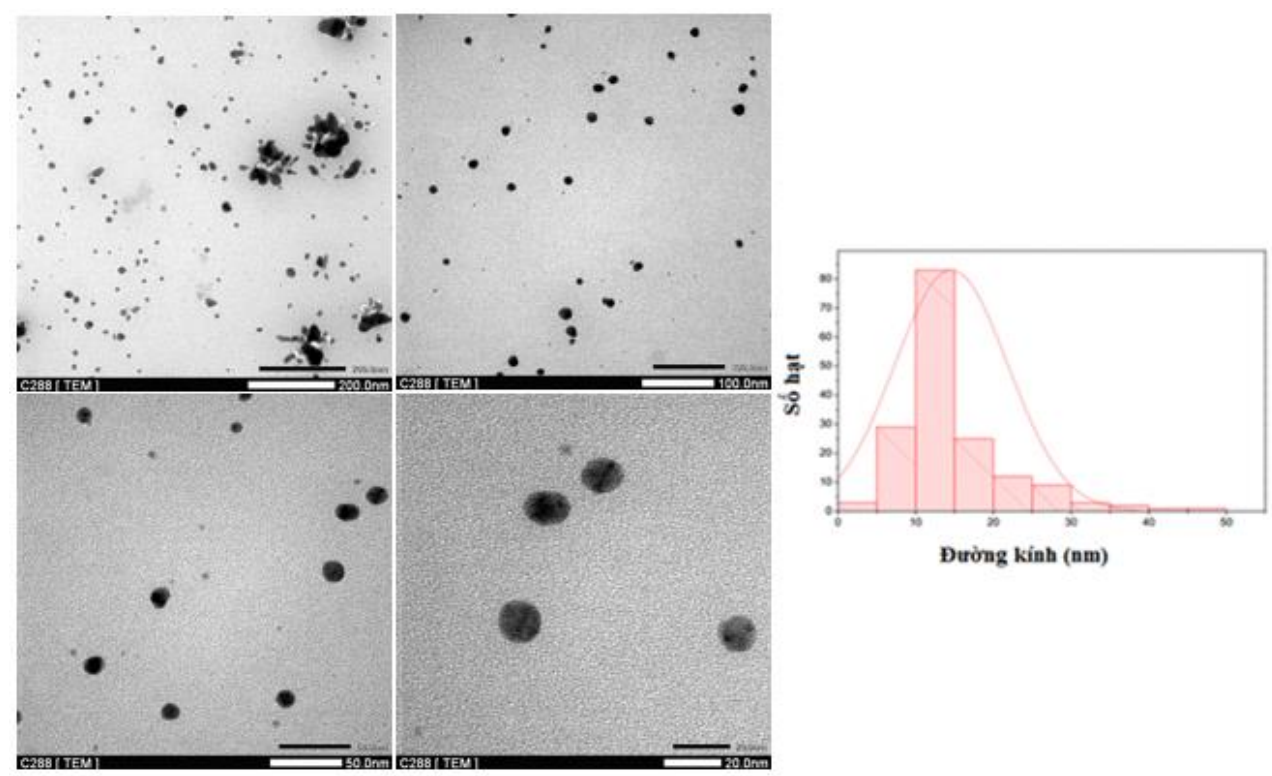

Hình 8. Ảnh TEM và phân bố kích thước AgNPs sau khi khử thêm bằng ascorbic acid 
Như vậy, thông qua việc tách nano $\mathrm{Ag}$ ra khỏi dung dịch, sau đó xác định hàm lượng ion $\mathrm{Ag}^{+}$còn lại trong dung dịch. Nồng độ nano $\mathrm{Ag}$ được xác định đã loại bỏ là 22 ppm. Như vậy, có thể kết luận dung dịch C318 có nồng độ nano bạc là khoảng 22 ppm, nồng độ ion $\mathrm{Ag}^{+}$còn lại chưa chuyển hóa hết là hơn $500 \mathrm{ppm}$.

Dung dịch nano Ag cần phải đưa vào sơn ở giai đoạn trước khi cho nhựa nhũ tương acrylic, với mục đích tăng khả năng phân tán trong sơn. Do đó khối lượng dung dịch nano $\mathrm{Ag}$ chỉ chiếm tối đa $10 \%$ khối lượng sơn khi thay thế lượng nước giải nhiệt (công thức điều chế sơn ở Bảng 1). Vì vậy để điều chế sơn có hàm lượng nano $\mathrm{Ag}$ từ $5 \mathrm{ppm}$ trở lên, cần thiết phải tổng hợp được dung dịch nano $\mathrm{Ag}$ ở nồng độ trên 50 ppm. Ngoài ra, cần phải đảm bảo kích thước hạt tương đối nhỏ $(<20 \mathrm{~nm})$ để đạt hiệu quả khảng khuẩn tốt.

Trong nghiên cứu này, độ chuyển hóa $\mathrm{Ag}^{+}$thành $\mathrm{Ag}$ được gia tăng bằng cách sử dụng thêm chất khử

\section{Bảng 2. Các chỉ tiêu và kết quả thử nghiệm sơn PLI65}

\begin{tabular}{|c|c|c|c|c|}
\hline STT & Tên chỉ tiêu & Mức quy định & Kết quả & Đánh giá \\
\hline 1 & Màu sắc & Theo mẫu chuẩn & - & - \\
\hline 2 & Độ mịn, $\mu$ m, không lớn hơn & 40 & 35 & Đạt \\
\hline 3 & $\begin{array}{l}\text { Độ bám dính của màng sơn trên nền vữa xi măng - cát, } \\
\text { theo điểm, không lớn hơn }\end{array}$ & 2 & 1 & Đạt \\
\hline \multirow[t]{2}{*}{4} & $\begin{array}{l}\text { Thời gian khô, giờ } \\
\text { - khô bề mặt, không lớn hơn }\end{array}$ & 1 & 0,25 & Đạt \\
\hline & - khô hoàn toàn (cấp 1), không lớn hơn & 5 & 2 & Đạt \\
\hline 5 & $\begin{array}{l}\text { Hàm lượng chất không bay hơi tính theo khối lượng, \%, } \\
\text { không nhỏ hơn }\end{array}$ & 50 & 55 & Đạt \\
\hline 6 & Độ nhớt, Pa.s (đo ở điều kiện RV4, SP4) & $20-30$ & 30 & Đạt \\
\hline 7 & Độ bền nước, giờ, không nhỏ hơn & 250 & 400 & Đạt \\
\hline 8 & $\begin{array}{l}\text { Độ bền kiềm, giờ, trong dung dịch } \mathrm{Ca}(\mathrm{OH})_{2} \text { bão hòa, } \mathrm{pH}= \\
14 \text {, không nhỏ hơn }\end{array}$ & 150 & 168 & Đạt \\
\hline 9 & Độ rửa trôi, chu kỳ, không nhỏ hơn & 450 & 3.000 & Đạt \\
\hline
\end{tabular}

\section{Bảng 3. Kết quả đo tỉ trọng của sơn PLI65}

\begin{tabular}{lccc}
\hline Số thứ tự mẫu & 1 & 2 & 3 \\
Khối lượng $(\mathrm{g})$ & 63,9411 & 63,8232 & 63,8330 \\
Tỉ trọng $(\mathrm{g} / \mathrm{mL})$ & 1,28 & 1,28 & 1,28 \\
Tỉ trọng trung bình mẫu $(\mathrm{g} / \mathrm{mL})$ & & $\mathbf{1 , 2 8}$ & \\
\hline
\end{tabular}

\section{3. Điều chế sơn PLI65-Ag}

Sơn PLI65-Ag được chế tạo bằng cách cho dung dịch nano $\mathrm{Ag}$ vào sơn trước khi thêm nhựa nhũ tương. Sự có mặt của dung dịch nano $\mathrm{Ag}$ đã có ảnh hưởng đến màu sắc của sơn PLI65-Ag (Hình 9). Mẫu có hàm lượng nano bạc $0,1 \mathrm{ppm}$ và $0,5 \mathrm{ppm}$ mạnh hơn là ascorbic acid. Mục đích là tổng hợp dung dịch nano $\mathrm{Ag}$ nồng độ khoảng 500 ppm mà vẫn duy trì được sự tồn tại của ion $\mathrm{Ag}$ trong dung dịch.

Hình 8 là ảnh TEM và phân bố kích thước hạt mẫu nano $\mathrm{Ag}$ nồng độ cao sau khi khử bằng ascorbic acid. Kết quả ảnh TEM cho thấy AgNPs có kích thước hạt lớn hơn các mẫu ở nồng độ thấp, đồng thời xuất hiện các hình dạng bất thường. Nguyên nhân có thể là do hoạt tính khử của ascorbic acid mạnh hơn so với glucose làm cho việc hình thành $\mathrm{Ag}$ diễn ra nhanh và không đồng đều.

\section{2. Điều chế sơn PLI65}

Các chỉ tiêu và kết quả thử nghiệm sơn PLI65 cũng như kết quả đo tỷ trọng của sơn được liệt kê trong Bảng 2 và 3 . Từ các kết quả đánh giá trên đã cho thấy sơn PLI65 đã đáp ứng hầu hết các tiêu chuẩn về sơn nhũ tương nội thất theo tiêu chuẩn Việt Nam. 


\begin{tabular}{|c|c|c|c|c|c|c|c|c|c|}
\hline Tolerances: & $\mathrm{DL}^{*}$ tol & $D a^{*}$ tol & $\mathrm{Db}^{*}$ tol & $D C^{*}$ tol & $\mathrm{DH}^{*}$ tol & Pif tol & Margin & I.c & \\
\hline D65-10 & 2.60 & 0.60 & 0.60 & 0.60 & 0.60 & 1.00 & 0.10 & 2.00 & \\
\hline Standard Name & & & $a^{*}$ & $b^{*}$ & $\mathrm{C}^{*}$ & $h^{\circ}$ & & & \\
\hline Non- $\mathrm{Ag}$ & & 22 & -0.16 & 0.18 & 0.24 & 131.30 & & & \\
\hline \begin{tabular}{|l} 
Trial Name \\
\end{tabular} & & & $\mathrm{Da}^{*}$ & $\mathrm{Db}^{*}$ & $D C^{*}$ & $\mathrm{DH}^{*}$ & DEcmo & \%STR-SUM & $\mathrm{P} F \mathrm{~F}$ D \\
\hline$x_{10}$ & & $58 \mathrm{D}$ & $0.82 R$ & $0.64 \mathrm{Y}$ & $0.82 \mathrm{~B}$ & $-0.64 Y$ & 1.61 & 87.16 & Failed \\
\hline$x^{5}$ & & 110 & $0.65 \mathrm{R}$ & $-0.48 \mathrm{~B}$ & $0.34 \mathrm{~B}$ & $-0.73 Y$ & 1.30 & 103.97 & Failed \\
\hline$x_{1}$ & & $92 \mathrm{~L}$ & $-0.30 \mathrm{G}$ & $0.58 \mathrm{Y}$ & $0.64 \mathrm{~B}$ & $-0.08 Y$ & 1.05 & 72.36 & Failed \\
\hline$\sqrt{05}$ & & $13 \mathrm{~L}$ & $-0.19 G$ & $-0.08 \mathrm{~B}$ & $0.12 \mathrm{~B}$ & $0.16 \mathrm{G}$ & 0.50 & 75.29 & Passed \\
\hline$\sqrt{01}$ & & $99 \mathrm{~L}$ & $-0.13 G$ & $-0.05 \mathrm{~B}$ & $0.12 \mathrm{~B}$ & $0.12 \mathrm{G}$ & 0.43 & 77.20 & Passed \\
\hline \multirow[t]{2}{*}{$<$} & & & & & & & & & $>$ \\
\hline & & & & 5 & & & 1 & & \\
\hline & & & & Non- & & & & & \\
\hline
\end{tabular}

Hình 9. Màu sắc và độ lệch màu của các mẫu sơn PLI65-Ag

Bảng 4. Nồng độ $\mathrm{Ag}^{+}$được phóng thích của sơn PLI65-Ag xác định bằng $\mathrm{AAS}$

\begin{tabular}{crrrrrrr}
\hline Nồng độ nano Ag trong sơn PLI65-Ag $(\mathbf{p p m})$ & $\mathbf{0 , 1}$ & $\mathbf{0 , 5}$ & $\mathbf{1 , 0}$ & $\mathbf{5 , 0}$ & $\mathbf{1 0 , 0}$ & $\mathbf{3 0 , 0}$ & $\mathbf{5 0 , 0}$ \\
\hline 1 giờ & 0,000 & 0,001 & 0,005 & 0,002 & 0,002 & 0,009 & 0,000 \\
2 giờ & 0,002 & 0,004 & 0,003 & 0,002 & 0,002 & 0,001 & 0,001 \\
4 giờ & 0,003 & 0,001 & 0,002 & 0,001 & 0,003 & 0,002 & 0,001 \\
48 giờ & 0,005 & 0,009 & 0,021 & 0,045 & 0,055 & 0,153 & 0,426 \\
\hline
\end{tabular}

Đo'n vị: ppm.

Các mẫu sơn PLI65-Ag với hàm lượng nano $\mathrm{Ag}$ khác nhau được khảo sát khả năng phóng thích ion $\mathrm{Ag}^{+}$sau khi được sơn lên giấy lọc và để khô tự nhiên trong 30 ngày. Nồng độ $\mathrm{Ag}^{+}$phóng thích vào môi trường nước từ sơn được xác định bằng $\mathrm{AAS}$ với kết quả được liệt kê trong Bảng 4. Kết quả cho thấy độ phóng thích tăng khi hàm lượng nano $\mathrm{Ag}$ trong sơn tăng. Ag ít bị phóng thích trong môi trường nước ở thời gian ngắn từ $1-4$ giờ. Trong khoảng thời gian này lượng $\mathrm{Ag}$ thoát ra khỏi màng sơn là không tuyến tính theo thời gian. Ở thời gian dài hơn như 48 giờ, $\mathrm{Ag}$ bị phóng thích ra môi trường nước nhiều hơn hẳn ở mẫu sơn có hàm lượng $\mathrm{Ag}$ cao từ 1,0-50,0 ppm.

\subsection{Khả năng kháng khuẩn}

Kết quả kháng khuẩn đối với vi khuẩn $E$. coli của sơn PLI65-Ag ở các nồng độ Ag khác nhau được hiển thị trên Hình 10 . Hình $10 \mathrm{a}$ và $10 \mathrm{~b}$ xuất hiện vòng kháng khuẩn ở các mẫu sơn PLI65-Ag lỏng chứng tỏ sơn dạng lỏng có khả năng diệt được $E$. coli. Đường kính tuy nhỏ nhưng cho thấy khả năng diệt vi khuẩn $E$. coli của nano $\mathrm{Ag}$ hiệu quả bên ngoài vùng được sơn. Như vậy, sơn có nano $\mathrm{Ag}$ ở các hàm lượng từ $0,1-10,0 \mathrm{ppm}$ có thể diệt được $E$. coli tại nơi tiếp xúc với sơn. Hình $10 \mathrm{c}$ và $10 \mathrm{~d}$ không xuất hiện vòng kháng khuẩn ở các mẫu sơn PLI65-Ag khô chứng tỏ sơn khi đã khô không có khả năng diệt E. coli ở các hàm lượng nano $\mathrm{Ag}$ trong sơn PLI65$\mathrm{Ag}$ từ $1,0-50,0 \mathrm{ppm}$. Nguyên nhân của kết quả này có thể là do mẫu sơn PLI65-Ag chưa khô màng còn tồn tại ion $\mathrm{Ag}^{+}$, nên chính ion này có tác dụng diệt E. coli. Mẫu sơn đã khô màng không có khả năng này do không tồn tại ion $\mathrm{Ag}^{+}$hoặc nano $\mathrm{Ag}$ không thể phân ly tạo thành $\mathrm{Ag}^{+}$. 

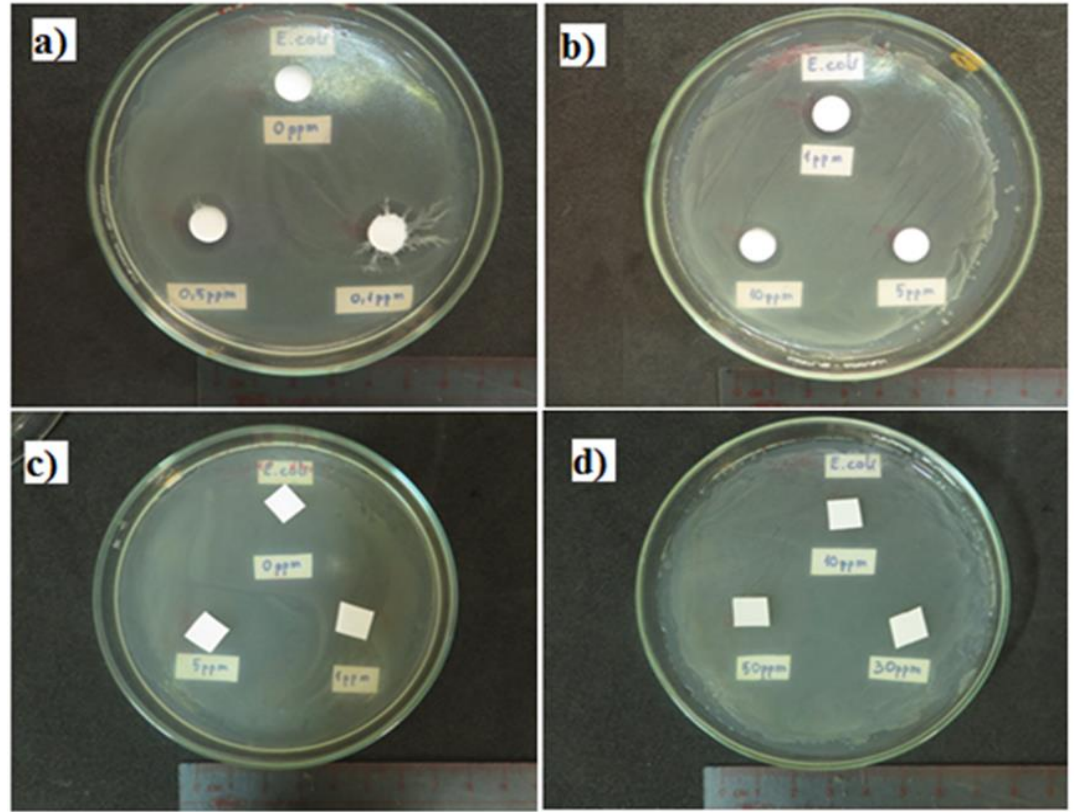

Hình 10. Thử nghiệm sơn PLI65-Ag trên E. coli

a) Son lỏng ở nồng độ $\mathrm{Ag}$ 0; 0,1 và 0,5 ppm,b) ở nồng độ $A g$ 1,0; 5,0 và 10,0 ppm,

c) Sơn khô tư nhiên trong 30 ngày ở nồng độ $A g$ 0; 0,1 và 0,5 ppm,

d) Son khô tư nhiên trong 30 ngày ở nồng độ $\mathrm{Ag}$ 10,0; 30,0 và 50,0 ppm
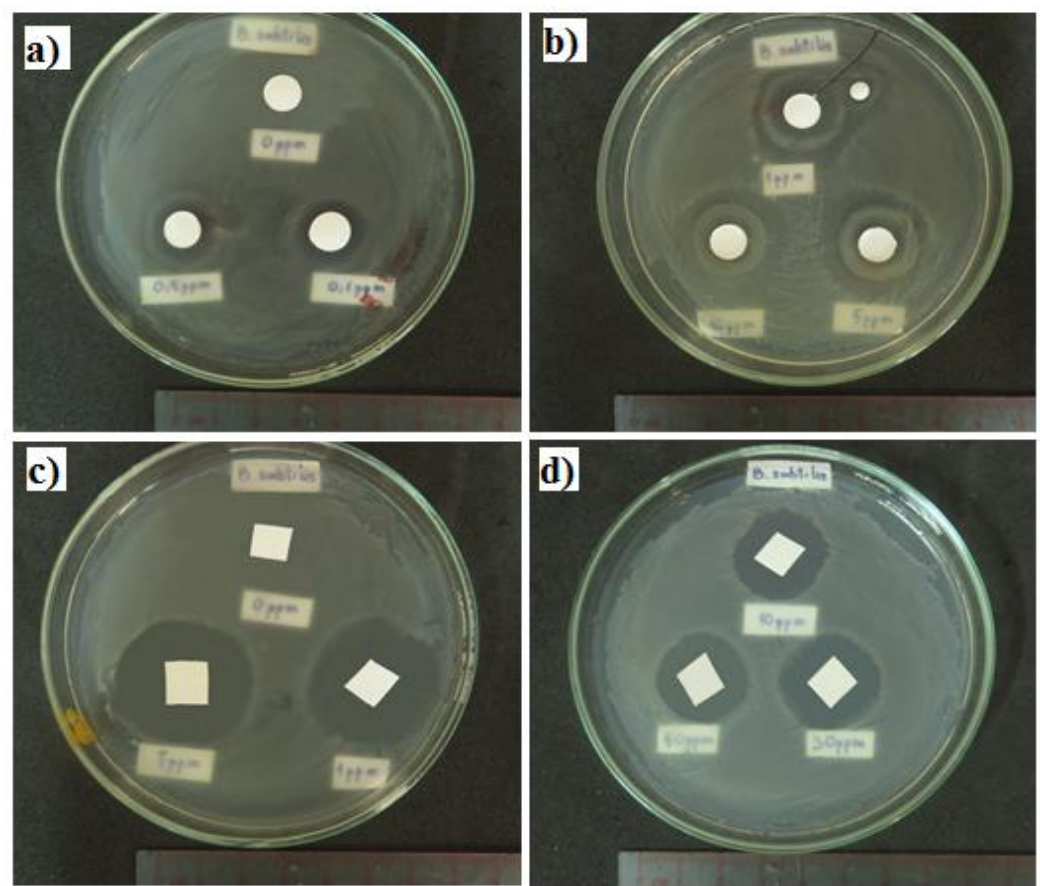

Hình 11. Thử nghiệm sơn PLI65-Ag trên B. subtilis

a) Son lỏng ở nồng độ $\mathrm{Ag}$ 0; 0,1 và 0,5 ppm,b) ở nồng độ Ag 1,0; 5,0 và 10,0 ppm,

c) Son khô tư nhiên trong 30 ngày ở nồng độ $\mathrm{Ag} 0 ; 0,1$ và $0,5 \mathrm{ppm}$,

d) Son khô tự nhiên trong 30 ngày ở nồng độ Ag 10,0; 30,0 và 50,0 ppm. 
Kết quả khảo sát đối với chủng vi khuẩn $B$. subtilis (Hình 11) cho thấy ở tất cả các mẫu sơn khi có nano $\mathrm{Ag}$ bất kể dạng lỏng hay khô đều cho thấy khả năng diệt vi khuẩn này so với các mẫu sơn không có nano Ag. Đối với các mẫu sơn khô, vòng kháng khuẩn có đường kính lớn hơn chứng tỏ hiệu quả diệt khuẩn tốt hơn so với sơn ở dạng lỏng. Nguyên nhân có thể là do lúc này không tồn tại ion $\mathrm{Ag}^{+}$mà thay vào đó là sự tăng hàm lượng của $\mathrm{Ag}$ dạng kim loại. Điều này cho thấy rõ khả năng diệt B. subtilis của nano $\mathrm{Ag}$ hơn hẳn ion $\mathrm{Ag}^{+}$. Ở Hình $11 \mathrm{c}$ và $11 \mathrm{~d}$, đường kính vòng kháng khuẩn của sơn có hàm lượng nano $\mathrm{Ag} 1,0 \mathrm{ppm}$ và 5,0 ppm lớn hơn so với sơn có hàm lượng nano $\mathrm{Ag}$ từ $10,0-50,0$ ppm. Nguyên nhân là do các mẫu sơn có hàm lượng nano $\mathrm{Ag}$ trên 10 ppm có thể đã xảy ra sự kết tụ của các hạt nano $\mathrm{Ag}$ làm cho kích thước của hạt tăng, dẫn đến hiệu quả diệt khuẩn kém hơn.

Như vậy, sơn nano Ag hiệu quả trong việc kháng $B$. subtilis, không hiệu quả trên $E$. coli. Trong màng sơn khô, cơ chế kháng khuẩn đối với $B$. subtilis là do nano $\mathrm{Ag}$, kháng E. coli do ion $\mathrm{Ag}^{+}$.

\section{KẾT LUẬN}

Trong nghiên cứu này, sơn nhũ tương nội thất có phụ gia kháng khuẩn là nano $\mathrm{Ag}$, đáp ứng hầu hết các tiêu chuẩn của Việt Nam, đã được điều chế và thử nghiệm thành công ở quy mô phòng thí nghiệm. Dung dịch nano $\mathrm{Ag}$ được cho vào sơn trước khi thêm nhựa nhũ tương, với tiêu chí không làm giảm các tính chất lý hóa của sơn, đồng thời vẫn duy trì được khả năng kháng khuẩn của nano $\mathrm{Ag}$ trong sơn. AgNPs hình cầu với kích thước tương đối đồng đều từ $8-12 \mathrm{~nm}$ đã được tổng hợp thành công bằng phương pháp khử hóa học, với tác nhân khử và chất bảo vệ thân thiện môi trường là glucose (nồng độ $0,4 \%$ ) và HPMC (nồng độ $0,01 \%$ ). Kết quả bước đầu cho thấy hiệu quả của nano $\mathrm{Ag}$ với vai trò phụ gia kháng khuẩn cho sơn nhũ tương khi hàm lượng nano $\mathrm{Ag}$ trong sơn là $0,1-0,5 \mathrm{ppm}$. Hiệu quả kháng khuẩn của nano $\mathrm{Ag}$ trong sơn nhũ tương được duy trì trong khoảng thời gian tối thiểu là 30 ngày.

\section{LỜI CẢM ƠN}

Nghiên cứu được tài trợ bởi Trường Đại học Khoa học Tự nhiên, ĐHQG-HCM trong khuôn khổ Đề tài mã số T2020-26. Nhóm tác giả xin chân thành cám ơn.

\section{TÀI LIỆU THAM KHẢO}

Ahamed, M., AlSalhi, M. S., \& Siddiqui, M. K. J. (2010). Silver nanoparticle applications and human health. Clinica Chimica Acta, 411(23),
1841-1848. doi:

https://doi.org/10.1016/j.cca.2010.08.016

Boev, C., \& Kiss, E. (2017). Hospital-acquired infections: current trends and prevention. Critical Care Nursing Clinics, 29(1), 51-65.

Bruchez, M., Moronne, M., Gin, P., Weiss, S., \& Alivisatos, A. P. (1998). Semiconductor Nanocrystals as Fluorescent Biological Labels. Science, 281(5385), 2013. doi: 10.1126/science.281.5385.2013

Cui, Y., Wei, Q., Park, H., \& Lieber, C. M. (2001). Nanowire Nanosensors for Highly Sensitive and Selective Detection of Biological and Chemical Species. Science, 293(5533), 1289. doi: 10.1126/science. 1062711

Dileep, P., Jacob, S., \& Narayanankutty, S. K. (2020). Functionalized nanosilica as an antimicrobial additive for waterborne paints. Progress in Organic Coatings, 142, 105574. doi: https://doi.org/10.1016/j.porgcoat.2020.105574

Dong, C., Zhang, X., \& Cai, H. (2014). Green synthesis of monodisperse silver nanoparticles using hydroxy propyl methyl cellulose. Journal of Alloys and Compounds, 583(1), 267-271. doi: https://doi.org/10.1016/j.jallcom.2013.08.207

Fabrega, J., Luoma, S. N., Tyler, C. R., Galloway, T. S., \& Lead, J. R. (2011). Silver nanoparticles: behaviour and effects in the aquatic environment. Environment international, 37(2), 517-531.

Furno, F., Morley, K. S., Wong, B., Sharp, B. L., Arnold, P. L., Howdle, S. M., . . . \& Reid, H. J. (2004). Silver nanoparticles and polymeric medical devices: a new approach to prevention of infection? Journal of Antimicrobial Chemotherapy, 54(6), 1019-1024. doi: 10.1093/jac/dkh478

Jiang, D., Xie, J., Chen, M., Li, D., Zhu, J., \& Qin, H. (2011). Facile route to silver submicron-sized particles and their catalytic activity towards 4nitrophenol reduction. Journal of Alloys and Compounds, 509(5), 1975-1979.

Khan, Z., Hussain, J. I., Kumar, S., \& Hashmi, A. A. (2011). Silver nanoplates and nanowires by a simple chemical reduction method. Colloids and Surfaces B: Biointerfaces, 86(1), 87-92.

Klasen, H. J. (2000). Historical review of the use of silver in the treatment of burns. I. Early uses. Burns, 26(2), 117-130. doi: https://doi.org/10.1016/S0305-4179(99)00108-4

Kumar, A., Vemula, P. K., Ajayan, P. M., \& John, G. (2008). Silver-nanoparticle-embedded antimicrobial paints based on vegetable oil. Nature Materials, 7(3), 236-241. doi: 10.1038/nmat2099

Liu, J., Li, X., \& Zeng, X. (2010). Silver nanoparticles prepared by chemical reduction- 
protection method, and their application in electrically conductive silver nanopaste. Journal of Alloys and Compounds, 494(1-2), 84-87.

Liu, L., Xu, X., Ye, Y., Ma, Y., Liu, Y., Lei, J., \& Yin, N. (2012). Electrolysis synthetic silver nanoparticles enhanced light emission from $\mathrm{CdSe}$ quantum dots. Thin Solid Films, 526, 127-132.

Liu, Y., Chen, S., Zhong, L., \& Wu, G. (2009). Preparation of high-stable silver nanoparticle dispersion by using sodium alginate as a stabilizer under gamma radiation. Radiation Physics and Chemistry, 78(4), 251-255.

Pauksch, L., Hartmann, S., Rohnke, M., Szalay, G., Alt, V., Schnettler, R., \& Lips, K. S. (2014). Biocompatibility of silver nanoparticles and silver ions in primary human mesenchymal stem cells and osteoblasts. Acta Biomaterialia, 10(1), 439-449. doi: https://doi.org/10.1016/j.actbio.2013.09.037

Popok, V., Stepanov, A., \& Odzhaev, V. (2005). Synthesis of silver nanoparticles by the ion implantation method and investigation of their optical properties. Journal of Applied Spectroscopy, 72(2), 229-234.

Raveendran, P., Fu, J., \& Wallen, S. L. (2006). A simple and "green" method for the synthesis of $\mathrm{Au}, \mathrm{Ag}$, and $\mathrm{Au}-\mathrm{Ag}$ alloy nanoparticles. Green Chemistry, 8(1), 34-38.
Sharma, V. K., Yngard, R. A., \& Lin, Y. (2009). Silver nanoparticles: Green synthesis and their antimicrobial activities. Advances in Colloid and Interface Science, 145(1), 83-96. doi: https://doi.org/10.1016/j.cis.2008.09.002

Shim, I.-K., Lee, Y. I., Lee, K. J., \& Joung, J. (2008). An organometallic route to highly monodispersed silver nanoparticles and their application to ink-jet printing. Materials Chemistry and Physics, 110(2-3), 316-321.

Sun, Y., \& Xia, Y. (2002). Shape-controlled synthesis of gold and silver nanoparticles. Science, 298(5601), 2176-2179.

Vitulli, G., Bernini, M., Bertozzi, S., Pitzalis, E., Salvadori, P., Coluccia, S., \& Martra, G. (2002). Nanoscale copper particles derived from solvated $\mathrm{Cu}$ atoms in the activation of molecular oxygen. Chemistry of materials, 14(3), 1183-1186.

Wani, I. A., Ganguly, A., Ahmed, J., \& Ahmad, T. (2011). Silver nanoparticles: ultrasonic wave assisted synthesis, optical characterization and surface area studies. Materials Letters, 65(3), 520-522.

Zuniga, J. M., \& Cortes, A. (2020). The role of additive manufacturing and antimicrobial polymers in the COVID-19 pandemic. Expert Review of Medical Devices, 17(6), 477-481. doi: 10.1080/17434440.2020.1756771 